\title{
Sex Determination in Nematode Germ Cells
}

\author{
Ronald E. Ellis \\ Department of Molecular Biology, Rowan University SOM, Stratford, NJ, USA
}

\author{
Keywords \\ Caenorhabditis elegans · Germ cell · Nematode · \\ Reproduction $\cdot$ Sex determination
}

\begin{abstract}
Background: Animal germ cells differentiate as sperm or as oocytes. These sexual fates are controlled by complex regulatory pathways to ensure that the proper gametes are made at the appropriate times. Summary: Nematodes like Caenorhabditis elegans and its close relatives are ideal models for studying how this regulation works, because the $\mathrm{XX}$ animals are self-fertile hermaphrodites that produce both sperm and oocytes. In these worms, germ cells use the same signal transduction pathway that functions in somatic cells. This pathway determines the activity of the transcription factor TRA-1, a Gli protein that can repress male genes. However, the pathway is extensively modified in germ cells, largely by the action of translational regulators like the PUF proteins. Many of these modifications play critical roles in allowing the XX hermaphrodites to make sperm in an otherwise female body. Finally, TRA-1 cooperates with chromatin regulators in the germ line to control the activity of fog- 1 and fog-3, which are essential for spermatogenesis. FOG-1 and FOG-3 work together to determine germ cell fates by blocking the translation of oogenic transcripts. Key Messages: Al-
\end{abstract}

though there is great diversity in how germ cell fates are controlled in other animals, many of the key nematode genes are conserved, and the critical role of translational regulators may be universal.

(c) 2022 S. Karger AG, Basel

\section{The Animal Germ Line}

The world teems with multicellular life, and even today new forms are evolving from unicellular ancestors [Kirk, 2005]. A critical trait shared by almost all of these groups is the use of dimorphic gametes. These differ dramatically in size and function: small ones like sperm are adapted for dispersal, and large ones like eggs for nurturing the new zygote [Parker et al., 1972]. Besides animals, this type of dimorphism is seen in many plants [Pereira et al., 2014], fungi [Nagy et al., 2018], and even in very simple creatures like Volvox [Geng et al., 2014].

Although complex life has originated many times, it seems likely that multicellular animals evolved only once [Cavalier-Smith, 2017]. Analyses of sponges and cnidarians, which diverged very early from bilaterian animals, suggest that our common ancestor had a simple organization and lacked most of the tissues found in modern animals. However, from the beginning, the ability to generate 
germ cells has formed a central part of the animal body plan. In some animals, like nematodes and fruit flies, the germ line is set aside from the rest of the organism early in development. By contrast, in mammals and many other animals the germ line is specified later [Extavour and Akam, 2003]. Indeed, in flatworms, it can even be re-established during tissue regeneration [Newmark et al., 2008].

Whatever approach is adopted to form the germ line, it has to produce cells that have exceptionally stable genomes and are capable of undergoing meiosis to produce haploid gametes. The meiotic program is sexually specialized in animals, with germ cells in males undergoing spermatogenesis to yield 4 spermatids and those in females undergoing oogenesis to yield a single mature oocyte and polar bodies.

\section{The Sexual Fate of Germ Cells Determines the}

Expression of Thousands of Genes

As with other animals, mature gametes from nematodes like Caenorhabditis elegans differ dramatically in size. Their internal makeup is also dimorphic, since spermatids are specialized for crawling, with extremely compact DNA, specialized organelles that control sperm activation, and a unique cytoskeleton [reviewed by Ellis and Stanfield, 2014]. By contrast, the oocyte is a large cell that carries the information and nutrients needed to nurture the embryo. It arrests in prophase of meiosis I and matures just before fertilization [reviewed by Huelgas-Morales and Greenstein, 2018]. These differences are reflected in highly divergent programs of gene expression, with more than a thousand genes specific to each sexual fate [Reinke et al., 2000, 2004; Ortiz et al., 2014; Tzur et al., 2018]. Nematode sperm and oocytes can therefore be considered representative of the dimorphism found in gametes throughout the animal phylogeny. This review will consider how so many genes can be so accurately controlled.

\section{Nematodes Are Ideal for Studying the Germ Line}

Sydney Brenner originally chose the nematode C. elegans as a model for studying the nervous system [Brenner, 1974; White, 2020], but it has several advantages that quickly made it a leading system for studying sex determination and the germ line. First, the 2 sexes are hermaphrodites and males [Maupas, 1900], which dramatically simplifies isolating mutations that cause sterility when homozygous [Brenner, 1974]. Second, these hermaphrodites are essentially modified females that produce sperm at the end of larval development, which al- lows the study of both male and female gametes in a single individual. Third, hermaphrodite development in C. elegans is specified by $2 \mathrm{X}$ chromosomes (XX), and male development by a single one (XO) [Nigon, 1949]. The lack of a Y chromosome simplifies the study of sex determination in germ cells, because the $\mathrm{Y}$ tends to carry genes needed for male reproduction [Bachtrog, 2013]. Fourth, these worms are transparent, which allows both gonad and germ cell development to be observed in living animals [Kimble and Hirsh, 1979]. Fifth, there have been important changes in mating systems during the recent evolution of Caenorhabditis, with at least 3 independent transitions to species with self-fertile hermaphrodites [Kiontke et al., 2011]; these species provide a window into how germ cell fates change under selection.

The germ line is the largest tissue in Caenorhabditis nematodes, which devote most of their resources to producing hundreds of offspring in just a few days. As with other animals, nematode germ cells have only a few decisions to make during development. The first is whether to proliferate by mitosis or enter meiosis and differentiate [reviewed by Kimble and Crittenden, 2007]. The next is sexual, whether to undergo spermatogenesis or oogenesis, which we discuss here. The last, which only occurs within the pool of female germ cells, is whether to complete oogenesis or undergo programmed cell death [reviewed by Gartner et al., 2008]. And if conditions are poor, larvae arrest in diapause and their germ cells enter quiescence, whereas adult germlines first shrink and then quiesce [Rashid et al., 2021].

All germ cells in males eventually undergo spermatogenesis, but in hermaphrodites only those differentiating early do so, whereas those differentiating during adulthood undergo oogenesis. Each spermatocyte produces 4 haploid spermatids; these are round cells that will extend a pseudopod when activated, so they can crawl towards oocytes. By contrast, each surviving oocyte is a large cell that arrests in meiosis I and only completes meiosis after fertilization.

\section{The Gonads Are Designed to Nurture and Regulate Germ Cells}

In hermaphrodites, the gonad consists of $2 \mathrm{U}$-shaped tubes that meet in a central uterus (Fig. 1a, c). The distal end of each tube is organized by a single large cell, the distal tip cell, forming a niche where germline stem cells can proliferate [Kimble and White, 1981]. This niche ends where the fingers of the distal tip cell intercalate with those of adjacent gonad sheath cells [Gordon et al., 2020]. These sheath cells help the distal tip cell regulate when germ cells enter meio- 
Fig. 1. The C. elegans gonad and germline. a Diagram of an XX hermaphrodite, with the gonad in red and the digestive system in green. Boxes show the location of expanded views. $\mathbf{b}$ Cross section of an $\mathrm{XX}$ hermaphrodite. The pseudocoelom is blue, gonad red, intestine green, muscles orange, seam cells dark gray, ventral nerve cord purple, yolk droplets yellow, and germ cells gray. c One-half of the hermaphrodite gonad. Sperm are blue, cell corpses dark gray, and other colors as above. $\mathbf{d}$ Diagram of an $\mathrm{XO}$ male, colored as in a. e Cross section of an XO male, colored as in $\mathbf{b}$. Spermatocytes are blue and residual bodies dark gray. $\mathbf{f}$ The male testis, colored as in $\mathbf{c}$ and $\mathbf{e}$.

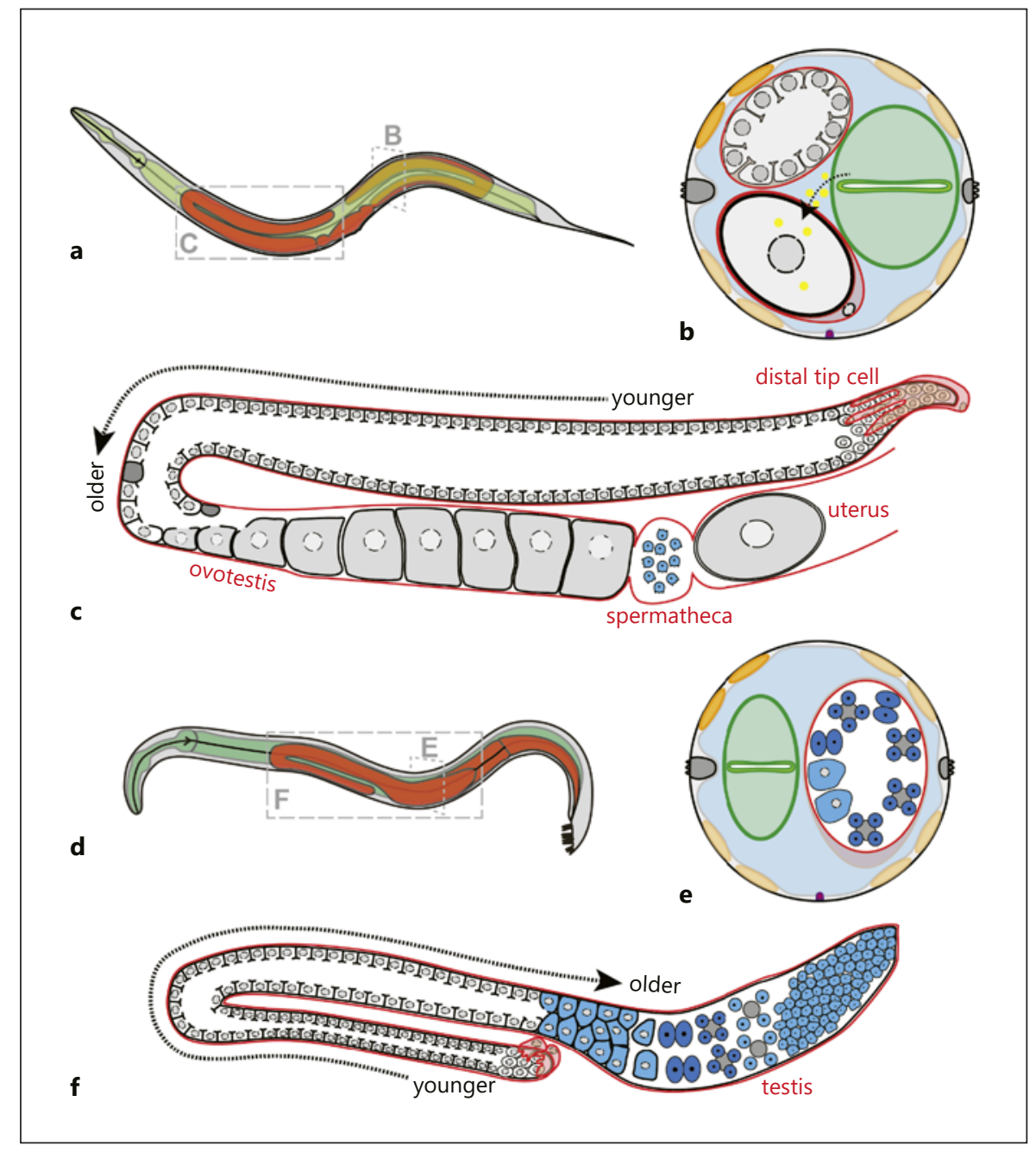

sis. They also influence the sex of germ cells, since ablation of sheath and spermathecal cells blocks the male fate of spermatogenesis [McCarter et al., 1997]. Finally, more proximal sheath cells contract to force mature oocytes into the spermatheca, a flexible tube with numerous internal folds where sperm are stored. Fertilized oocytes then pass through the spermathecal/uterine valve into the uterus, and soon afterwards the new embryos are laid.

In males, the gonad forms a single J-shaped tube (Fig. 1d, f). At one end, the 2 distal tip cells organize the stem cell niche. The testis reflexes, with spermatogenesis occurring past the bend, and mature spermatids being stored at the end. The testis abuts the seminal vesicle and vas deferens, through which sperm pass during mating, so they can exit from the cloaca into the hermaphrodite vulva. Cells in the vas deferens secrete components of the seminal fluid, which activate sperm and aid in mating.

Sex Determination in Nematode Germ Cells
In both sexes, the gonad occupies much of the center of the body. Nematodes have a simple body plan, with the hypodermis, nerves, and muscle forming a hollow tube. This tube is filled with fluid (the pseudocoelom) in which the gonad and intestine are located (Fig. 1b, e). This central location makes it easy for the gonad to communicate with other tissues and receive the yolk and other nutrients needed to produce eggs or sperm.

\section{A Core Sex-Determination Pathway Controls Both Germline and Somatic Fates}

In nematodes, sex determination is controlled by a core signal transduction pathway that coordinates development throughout the body (Fig. 2a) [reviewed by Zarkower, 2006]. Although many features of this pathway are 
Fig. 2. The core sex-determination pathway for germ cells. Proteins that promote male fates are shaded blue, and those that promote female fates are shaded magenta. An inhibition arrow indicates negative regulation, and an arrow indicates positive regulation. Line thickness denotes the strength of interactions, with dashed lines marking very weak interactions. Dotted lines show import into the nucleus. a Outline of the core sex-determination pathway. $\mathbf{b}$ The regulatory interactions in adult males, where HER-1 inactivates TRA-2, allowing the FEM complex to degrade TRA1. Some TRA-1 is needed to work with TRR-1 and the Tip60 complex to promote spermatogenesis by inducing transcription of $f \circ g$-3. c The regulatory interactions in adult hermaphrodites, where TRA-2 is cleaved to form TRA- $2_{\text {ic }}$, which inactivates FEM-3. This allows TRA-1 to survive and be cleaved to form a Gli repressor that turns off genes like fog-3 (see text for details).

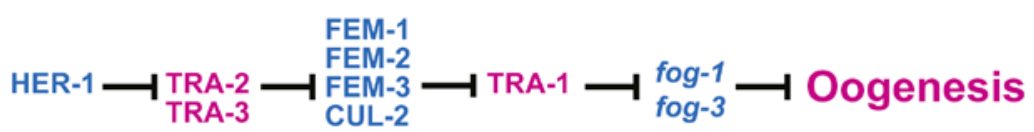

a

Adult $X O$ male germ cells

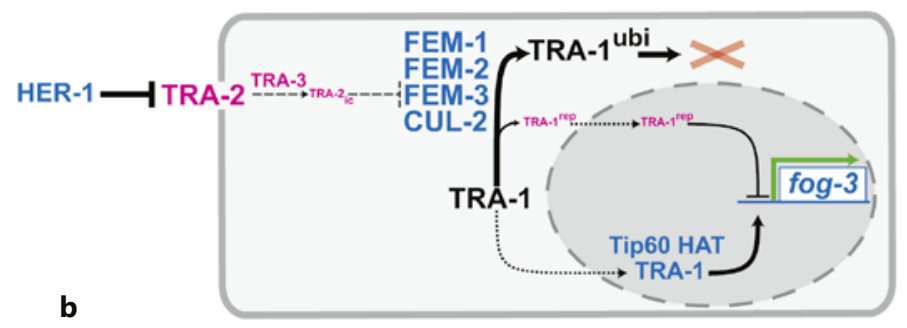

Sperm

Adult $X X$ hermaphrodite germ cells

C

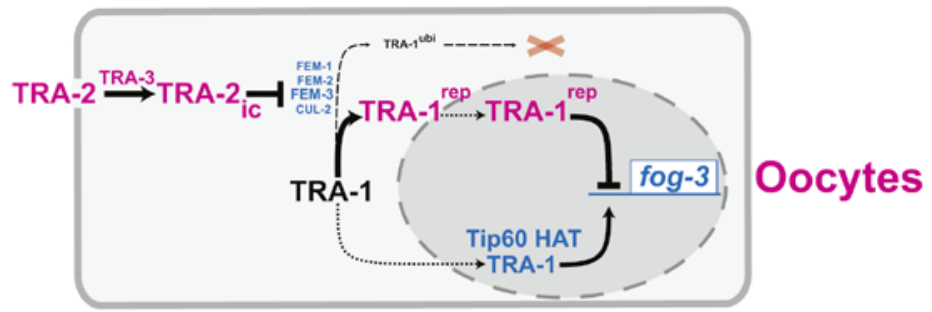

unique to worms, the TRA-2 receptor is distantly related to Patched [Kuwabara et al., 1992], and the TRA-1 transcription factor is a homolog of Cubitus interruptus and the Gli proteins [Zarkower and Hodgkin, 1992]. Thus, worm sex determination might share its origins with the Hedgehog pathway [Kuwabara et al., 1992; reviewed by Burglin and Kuwabara, 2006].

The initial cue that determines sex is the ratio of $\mathrm{X}$ chromosomes to autosomes [Madl and Herman, 1979], which regulates the activity of the xol-1 gene [Farboud et al., 2013]. As a result, XO animals have high levels of XOL-1 protein, and XX animals have low levels. In XO worms XOL-1 prevents the SDC complex from repressing the transcription of her-1 [Chu et al., 2002], allowing it to produce a small, secreted protein [Trent et al., 1991]. Genetic mosaic experiments showed that this secreted protein, HER-1, is a sex hormone that promotes male development throughout the body [Hunter and Wood, 1992]. Furthermore, HER-1 also controls germ cell fates, causing them to differentiate as sperm. Thus, a signal from the soma plays a major role in determining the sexual fate of nematode germ cells.
How does HER-1 do this? Its target, TRA-2, is a transmembrane protein [Kuwabara et al., 1992] that is required for hermaphrodite development [Hodgkin and Brenner, 1977]. Mutations that prevent HER-1 from binding TRA-2 cause XO animals to become hermaphrodites [Kuwabara, 1996a], as expected if HER-1 represses TRA-2 (Fig. 2b, c). Their physical interaction appears to prevent TRA-2 itself from being cleaved by the calpain protease TRA-3 [Barnes and Hodgkin, 1996; Sokol and Kuwabara, 2000], which would release a key intracellular fragment called TRA- $2_{\mathrm{ic}}$. C. elegans germ cells produce a second tra-2 transcript that directly codes for this intracellular fragment [Kuwabara and Kimble, 1995; Kuwabara et al., 1998], providing an alternative source in the germ line. However, this smaller transcript is not found in the related nematode C. briggsae [Kuwabara, 1996b], so it is not fundamental to how the pathway works.

The ultimate target of TRA- $2_{\text {ic }}$ is TRA- 1 , a Gli transcription factor [Zarkower and Hodgkin, 1992] that controls all sexual fates in both the soma and germ line. $\mathrm{Mu}$ tations that result in constitutive TRA-1 activity cause XX 
and $\mathrm{XO}$ animals to develop as females and make oocytes [Hodgkin, 1980, 1987; de Bono et al., 1995], whereas mutations that inactivate tra-1 cause them to develop as males [Hodgkin and Brenner, 1977; Hodgkin, 1987]. Surprisingly, these tra-1 mutant males produce sperm early in life but oocytes in old age, which reveals a secondary role in sustaining spermatogenesis [Hodgkin, 1987; Schedl et al., 1989]. Thus TRA-1 controls germ cell fates but is not absolutely necessary for either spermatogenesis or oogenesis to occur. Like other Gli proteins, TRA-1 is cleaved to form a repressor [Schvarzstein and Spence, 2006], which turns off many males genes [Berkseth et al., 2013]. These include fog-3 [Chen and Ellis, 2000] and fog1 [Jin et al., 2001b], which directly specify male germ cell fates.

TRA-1 is degraded in XO animals to prevent female development [Schvarzstein and Spence, 2006]. This process is controlled by $3 \mathrm{fem}$ genes, which act downstream of TRA- $2_{\text {ic }}$ to promote male development and spermatogenesis [Kimble et al., 1984; Hodgkin, 1986]. The FEM-1 protein contains ankyrin repeats [Spence et al., 1990], FEM-2 is a phosphatase [Chin-Sang and Spence, 1996], and FEM-3 is novel [Ahringer et al., 1992]. Together, they form a complex with CUL-2 that ubiquitinates TRA-1 [Starostina et al., 2007]. The CDC-48 proteins [Sasagawa et al., 2009] and 3 of their UBX co-factors aid in this process [Sasagawa et al., 2010]. By contrast, in XX animals TRA- $2_{\text {ic }}$ is active and binds FEM-3 [Mehra et al., 1999], which protects TRA-1 from the FEM complex and prevents its degradation.

TRA-1 degradation is carried out by the proteosome, which contains both a catalytic unit and a regulatory particle. Studies in yeast revealed that some components of the regulatory particle are not essential [van Nocker et al., 1996]. Surprisingly, mutations in the C. elegans homolog of one of these components, $r p n-10$, are viable and cause all germ cells to differentiate as oocytes [Shimada et al., 2006]. A similar result was obtained for another component of the regulatory particle, $r p n-12$ [Fernando et al., 2021]. Although knocking down tra-1 can restore self-fertility to mutants of either gene, knocking down tra-2 is most effective at suppressing $r p n-10$. Thus, mutations in these 2 genes might reveal different aspects of proteosomal regulation. $\mathrm{RPN}-12$, at least, appears to be a good candidate for directly promoting TRA-1 degradation.

TRA-2 not only regulates the FEM complex but also directly binds TRA-1 in an interaction that is blocked by several mixomorphic tra-2 alleles [Lum et al., 2000; Wang and Kimble, 2001]. These mutations cause all her-

Sex Determination in Nematode Germ Cells maphrodite germ cells to become oocytes rather than sperm but have only minor effects on somatic tissues [Doniach, 1986; Kuwabara et al., 1998]. Thus, it appears that TRA-2 $2_{\text {ic }}$ interacts with TRA-1 to promote spermatogenesis. This surprising result, along with the role of TRA-1 in both turning off and sustaining spermatogenesis, highlights the frequency of dual functions among sex-determining genes. Since the mixomorphic alleles do not affect male germ cell fates, the interaction between TRA- $2_{\text {ic }}$ and TRA-1 might occur only in XX animals, or it might not be strong enough to perturb germ cell fates in males.

\section{Chromatin Regulators Cooperate with TRA-1 to Control Cell Fates}

Like most transcription factors, TRA-1 cooperates with chromatin regulators to specify germ cell fates. The nucleosome remodeling factor (or NURF) complex is needed during larval development to promote spermatogenesis in C. briggsae males and hermaphrodites [Chen et al., 2014], where it acts independently of TRA-1 to promote the expression of $f \circ g-1$ and $f \circ g$ - 3 . The simplest model is that the NURF complex opens the chromatin so that it is accessible to TRA-1. However, the nurf-1 locus is complex, and in C. elegans one isoform promotes spermatogenesis, whereas another favors oogenesis [Xu et al., 2019]. Thus, a balancing act between different products of this complex locus seem to be critical for specifying germ cell fates.

In addition, TRR-1, a homolog of TRRAP, works with the Tip60 Histone Acetyl Transferase complex to promote spermatogenesis [Guo et al., 2013]. Although trr-1 null alleles are sickly and sterile, weak alleles cause animals of both sexes to make oocytes instead of sperm. Surprisingly, this phenotype is suppressed by tra- $1 \mathrm{mu}$ tations. One possible explanation is that full-length TRA-1, like full-length Cubitus interruptus, is an activator of transcription. If so, it could work with TRR-1 and the Tip60 complex to turn on sperm genes [Guo et al., 2013].

Finally, the WDR-5 proteins act as part of the COMPASS complex in nematodes to regulate many aspects of germline development by methylating lysine 4 of histone 3 [Li and Kelly, 2011]. Surprisingly, inactivation of 2 of the $3 w d r-5$ genes causes hermaphrodites to make sperm throughout their lives [Li and Kelly, 2014]. However, this effect does not involve other members of the COMPASS complex. Instead, these WDR-5 proteins are needed for TRA-1 repressor to associate with the chromatin and block transcription of fog-3. 


\section{The Translational Regulators FOG-1 and FOG-3 Specify Germ Cell Fates}

In nematodes, 2 genes directly control germ cell fates, fog- 1 and $f \circ g$ - 3 . We know they are essential for spermatogenesis but not other sexual fates since mutations in either gene cause germ cells to differentiate as oocytes instead of sperm, but do not affect other tissues [Barton and Kimble, 1990; Ellis and Kimble, 1995]. In addition, double mutants with tra-1 or other sex-determining genes confirm that fog- 1 and fog-3 act at the end of the pathway. Finally, fog- 1 and fog- 3 are directly regulated by TRA-1, with multiple Gli binding sites in each promoter [Chen and Ellis, 2000; Jin et al., 2001b]. Thus, these 2 genes act in response to the global regulatory pathway to choose between spermatogenesis and oogenesis.

The only qualification to this model is that mutations in $f s h r-1$, which encodes a glycopeptide hormone receptor that acts in somatic tissues, can work in combination with translational regulatory mutations to suppress fog- 1 or fog-3 [Cho et al., 2007]. This trait is not yet understood.

Although FEM-1, FEM-2, and FEM-3 are also needed for spermatogenesis in C. elegans [Kimble et al., 1984; Hodgkin, 1986], they are dispensable in C. briggsae [Hill et al., 2006], despite the fact that FEM-3 does play a small role downstream of TRA-1 [Hill and Haag, 2009]. These results suggest that the fem genes are not central to this cell fate decision. Instead, they are likely to help regulate FOG-1, FOG-3, or an associated protein in C. elegans in addition to ubiquitinating TRA-1.

How do FOG-1 and FOG-3 control germ cell fates? FOG- 1 is a cytoplasmic polyadenylation element binding (CPEB) protein [Luitjens et al., 2000; Jin et al., 2001b]. It has 2 RNA recognition motifs and a zinc-finger domain, all of which are required for function. Moreover, FOG-1 binds RNA in vitro [Jin et al., 2001a]. During development, FOG-1 can be detected in the germ line of L3 larvae around the time that sex determination is beginning and it is expressed before the earliest sperm proteins [Lamont and Kimble, 2007]. These results support the idea that FOG-1 specifies male germ cell fates.

FOG-3 is a member of the Tob/BTG family of proteins [Chen et al., 2000]. Mammalian homologs interact with CPEB proteins and regulate mRNA de-adenylation by the CCR4-CAF1-NOT complex [reviewed by Mauxion et al., 2009]. The members of this complex are expressed at high levels in the nematode germline, but their mutant phenotypes are broad and complex [Molin and Puisieux, 2005; Nousch et al., 2013], which has obscured any role they might play with FOG-3 in sex determination.
Like other Tob proteins, FOG-3 is regulated by its phosphorylation state [Lee et al., 2011]. Lack of phosphorylation is critical for the initiation of spermatogenesis in both sexes, whereas phosphorylated T108 and S260 are needed to maintain spermatogenesis in adult males. Although Map kinase activity promotes spermatogenesis in worms [Lee et al., 2007b], it is unlikely to control these target sites, since unphosphorylated FOG-3 is needed to initiate spermatogenesis. Thus, the kinase that modifies FOG-3 remains unknown.

FOG-1 and FOG-3 co-immunoprecipitate and are both required for male germ cell fates, so they appear to form a complex [Noble et al., 2016]. Moreover, FOG-3 can dimerize, and its dimers assemble into large arrays [Aoki et al., 2018]. Thus, the full structure of this regulatory complex could be very large. Although studies of mammalian Tob proteins suggest that CCR4 and CAF1 homologs could also be part of this complex, current data do not seem to support this hypothesis [Aoki et al., 2018].

The mRNAs that are isolated from FOG-1 or FOG-3 precipitates include a large set of overlapping targets [Noble et al., 2016]. Furthermore, these common targets are mostly oogenic messages, which suggests that FOG-1 and FOG-3 might work by blocking their translation [Noble et al., 2016; Aoki et al., 2018]. Thus, the simplest model is that FOG-1 and FOG-3 select male germ cell fates by blocking the translation of mRNAs that encode oogenic proteins. This model fits nicely with a study showing that the expression patterns of most genes that act in oogenesis are primarily regulated by their $3^{\prime}$-UTRs [Merritt et al., 2008].

\section{Competing PolyA Polymerases Help Determine Germ Cell Fates}

Since the FOG-3/FOG-1 complex blocks translation of messenger RNAs, does it do so through de-adenylation of the targets? Observation of key mRNAs supports the idea that polyadenylation state is important. For example, fem-3 messages have longer polyA tails in germ lines where FEM-3 is actively specifying male fates [Ahringer and Kimble, 1991; Ahringer et al., 1992]. However, 2 polyA polymerases also play a major role in regulating the sexual fates of germ cells, which complicates the resolution of this question.

These 2 polymerases include the same core subunit, GLD-2, a regulatory polyA polymerase [Wang et al., 2002]. GLD-2 controls many aspects of germ cell development [Kadyk and Kimble, 1998]. When bound to GLD-3, it promotes entry into meiosis [Eckmann et al., 
2004] and spermatogenesis [Eckmann et al., 2002]. GLD2 can also bind RNP-8, forming a complex that promotes oogenesis [Kim et al., 2009]. These 2 polyA polymerases, GLD-2/GLD-3 and GLD-2/RNP-8, compete with each other to specify germ cell fates. However, the effects of mutations in gld-3 or $r n p-8$ are small in isolation and only become dramatic when combined with other mutations that influence sex. These results suggest that these alternative polyA polymerases might reinforce male or female germ cell fates by forming part of 2 larger competitive regulatory systems.

\section{A Transcriptional Network Operates Downstream of FOG-1 and FOG-3}

These studies show that FOG-1 and FOG-3 use a posttranscriptional mechanism to control the sperm fate decision and that this mechanism probably involves the control of translation. Despite this, subsequent spermatogenesis relies heavily on transcriptional regulation [Merritt et al., 2008]. There does not seem to be a single master transcriptional regulator for this fate, but instead several transcription factors act together to control sperm differentiation. For example, the transcription factor SPE-44 promotes the expression of a large number of sperm genes and is required for germ cells to complete spermatogenesis [Kulkarni et al., 2012]. One of its targets is the GATA transcription factor ELT-1, which controls the expression of many of the Major Sperm Protein ( $m s p$ ) genes [Shim, 1999; del Castillo-Olivares et al., 2009] and also regulates development in other tissues. Finally, the nuclear hormone receptor NHR-23 controls a third set of sperm genes [Ragle et al., 2020]. Since some sperm genes are not regulated by any of these factors, additional ones probably remain to be discovered.

As one might expect if FOG-1 and FOG-3 are broad regulators of translation in the germ line, they also influence the decision of cells to proliferate or enter meiosis [Thompson et al., 2005; Snow et al., 2013]. To do this, they cooperate with the PUF proteins FBF-1 and FBF-2, and the precise dose of both FOG-1 and of FOG-3 plays a critical role in determining which outcome occurs. Thus, they resemble several other translational regulators (to be discussed below) that also control both proliferation and germ cell fates. The broad overlap in function of these regulators suggests that the control of sexual fates and cell division programs are inextricably linked in the germ line [Kimble and Page, 2007].

Sex Determination in Nematode Germ Cells

\section{The Sex-Determination Pathway Is Modified in Hermaphrodite Germ Cells}

Although the core pathway regulates sexual fates in both the soma and the germ line, it has to be modified in hermaphrodite germ cells. These hermaphrodites face the complex task of producing male germ cells in a female gonad and then producing female germ cells from the same population of stem cells. Thus, the somatic HER-1 signal is not sufficient on its own. As a result, sex determination differs extensively between soma and germ line in species like C. elegans, but there are often important modifications in male/female species as well, as first observed in the fruit fly Drosophila melanogaster.

\section{GLD-1 and FOG-2 Regulate tra-2 Messages to}

Promote XX Spermatogenesis

In C. elegans, hermaphrodite spermatogenesis depends on regulatory steps that lower the expression of TRA-2 in XX germ cells. The first evidence for this system was the identification of mutations in tra-2 that cause a gain-of-function $(g f)$ in the hermaphrodite germ line, resulting in XX animals that only make oocytes [Doniach, 1986]. These mutations do not alter the TRA-2 protein, but instead map to the 3'-UTR [Okkema and Kimble, 1991; Kuwabara et al., 1992] where they affect one or both copies of a repeated element, altering translation of the tra-2 mRNA [Goodwin et al., 1993]. Five of these $g f$ mutations affect only the XX germ line but the sixth, e2020, also weakly affects the XO germ line and some aspects of somatic development [Doniach, 1986]. The e2020 mutation is a large deletion that removes both repeats entirely, plus flanking DNA [Kuwabara et al., 1992], which could explain its more severe phenotype.

Regulation of tra- 2 through these direct repeats is controlled by 2 genes, fog- 2 and gld-1. Loss-of-function mutations in fog- 2 are recessive and result in the same phenotype as the gf mutations in tra-2 [Schedl and Kimble, 1988]. Thus, FOG-2 is required for XX animals to make sperm, but not for XO animals. The FOG-2 protein contains an $\mathrm{F}$ box, but it is not known if it functions as part of an E3 ubiquitin ligase complex [Clifford et al., 2000]. FOG-2 is otherwise unique, evolved recently, and exists only in C. elegans [Nayak et al., 2005].

The best clue to FOG-2's function is that it binds GLD1 [Clifford et al., 2000]. GLD-1 is also required for spermatogenesis in hermaphrodites but not in males [Francis et al., 1995a]. However, gld-1 mutations cause a complex array of additional phenotypes like tumorigenesis, because they also affect other aspects of germline develop- 
ment [Francis et al., 1995b]. The GLD-1 protein contains a KH domain that binds RNA [Jones and Schedl, 1995], and GLD-1 precipitates contain many mRNAs involved in oogenesis [Lee and Schedl, 2001]. Furthermore, GLD1 binds tra-2 directly, in an interaction that depends on the repeat elements in the 3 '-UTR [Jan et al., 1999]. Thus, the simplest model is that a GLD-1/FOG-2 complex controls sexual fate in germ cells by repressing the translation of tra-2 messenger RNAs. This repression should result in less TRA-2, allowing spermatogenesis in young hermaphrodites.

In XX hermaphrodites, the FOG-2 protein is expressed in mitotic germ cells and in the early stages of meiosis [Clifford et al., 2000] where it would be needed to control sexual fates. GLD-1 is also expressed in these regions, but the protein remains detectable throughout the pachytene stage of meiosis I, as expected from its broad role in regulating oocyte development [Jones et al., 1996]. Although both proteins are expressed in males, they have no known functions in them.

A few alleles of gld-1 highlight its critical role in sex determination. The mutation gld-1(q126) causes hermaphrodites to make oocytes instead of sperm but otherwise has little effect [Francis et al., 1995a]. This allele changes a single amino acid near the end of the GLD-1/ Quaking conserved region [Jones and Schedl, 1995]. Although it does not affect GLD-1's general ability to bind RNA, it strongly decreases binding to tra-2 messages, which could explain the Fog phenotype [Lee and Schedl, 2001]. By contrast, missense mutations like gld-1(q93) cause hermaphrodites to make only sperm [Francis et al., 1995a]. These mutations map to 2 amino acids just outside the KH domain [Jones and Schedl, 1995] and decrease the ability of GLD- 1 to bind $g l p-1$ messages [Hu et al., 2019]. It is not clear how they affect sex determination.

In fact, the overall mechanism by which FOG-2 and GLD-1 work remains mysterious. For example, GLD-1 represses the translation of a large number of targets [e.g., Lee and Schedl, 2004; Scheckel et al., 2012]. Furthermore, the binding sites in these target mRNAs contain the same $\mathrm{UACU}(\mathrm{C} / \mathrm{A}) \mathrm{A}$ sequence element found in tra-2 [Ryder et al., 2004]. Thus, it is not clear why FOG-2 should be needed for GLD-1 to repress tra-2 mRNA translation, when FOG-2 is not needed for other GLD-1 targets. One possibility is that GLD- 1 binds both the $5^{\prime}$ and $3^{\prime}$-ends of the rme-2 message, but only the $3^{\prime}$-end of tra-2, a difference that might be remedied by FOG-2 activity [Lee and Schedl, 2001]. An additional puzzle is the fact that fog-2 mutations can still influence germ cell fate in tra$2(e 2020 g f)$ animals, even though e2020 completely re- moves the known GLD-1 binding sites from the transcript [Hu et al., 2019]. Analyses of the DEAD box helicase SACY-1 also reveal differences between mutations in FOG-2 and in the tra-2 target site [Kim et al., 2012]. Knocking down SACY-1 suppresses fog- 2 mutants but not tra-2(e2020) mutants. Thus, both of these studies suggest FOG-2 does not function exclusively through the known GLD-1 target sequences in the $3^{\prime}$-UTR of tra- 2 .

\section{TRA-2 Is Regulated by a Different Mechanism in C.} briggsae Germ Cells

Although C. briggsae lacks a fog-2 gene [Nayak et al., 2005], its XX animals nonetheless undergo hermaphrodite development. To do this they utilize SHE-1, a novel F-box protein that is unrelated to FOG-2 [Guo et al., 2009]. SHE-1 can bind SKR-1, a critical component of the SCF ubiquitin ligase complex, and mutations that alter its F box prevent SHE-1 from working. Thus, SHE-1 might control the stability of a target protein. Although this target has not been identified, analysis of double mutants suggests that SHE-1 acts upstream of TRA-2 [Guo et al., 2009].

Despite the superficial similarity between SHE-1 and FOG-2, SHE-1 does not bind C. briggsae GLD-1 [Guo et al., 2009], and Cbr-GLD-1 does not seem to promote spermatogenesis [Nayak et al., 2005; Beadell et al., 2011]. Indeed, knocking down Cbr-gld-1 by RNA interference causes spermatogenesis. Instead, Cbr-GLD-1 regulates the expression of PUF-8 [Beadell et al., 2011], and CbrGLD-1 expression is itself controlled by PUF-2 and PUF1.2 [Liu et al., 2012]. These PUF proteins are related to Pumilio and form part of a conserved family that regulates cell fates in both the germ line and soma [reviewed by Wang and Voronina, 2020]. How this translational module impinges on the sex-determination pathway in $C$. briggsae remains unknown.

\section{PUF Proteins Turn Off Spermatogenesis by Repressing} fem-3 in C. elegans Hermaphrodites

Just as a complex system for regulating TRA-2 activity in hermaphrodites was revealed by Fog mutations, which feminize the germ line, a system for controlling FEM-3 was discovered through Mog mutations, which masculinize the germline. These mutations in fem-3 cause XX animals to make sperm throughout their lives, without affecting other sexual decisions [Barton et al., 1987]. Each of them alters a regulatory site in the $3^{\prime}$-UTR of the message [Ahringer and Kimble, 1991], and this site is a target for repression by the PUF proteins FBF-1 and FBF-2 [Zhang et al., 1997]. When both FBF proteins are 
inactivated by RNA interference, the double mutants make only sperm, just like the fem-3(gf) mutants. Thus, this regulatory system is crucial for allowing C. elegans hermaphrodites to switch from spermatogenesis to oogenesis.

At least one nanos gene in C. elegans cooperates in this regulatory step [Kraemer et al., 1999]. The NOS-3 protein physically interacts with FBF to regulate the expression of fem-3 in germ cells. Similar studies in Drosophila found that Pumilio interacts with Nanos to control their hunchback mRNA target [Sonoda and Wharton, 1999]. However, mutations in nos-3 have a weak effect on their own, probably because nos- 1 and nos-2 help turn off fem-3. Surprisingly, neither NOS-1 nor NOS-2 seems to bind the FBF proteins directly [Kraemer et al., 1999].

Finally, LARP-1 contains an LA motif and binds RNA [Nykamp et al., 2008]. Like FBF, it is also redundant with NOS-3 in the control of germ cell fates, and the majority of nos-3; larp-1 double mutants are Mog [Zanin et al., 2010]. However, larp-1 mutations appear to act by increasing the levels of fem-3 transcripts in the germ line, rather than by altering their translation. Thus, there might be multiple levels of regulation controlling these fem-3 transcripts.

\section{PUF Proteins Regulate Germ Cell Fates at Many \\ Decision Points}

The ancient PUF family of proteins not only regulates FEM-3 but also plays a central role in coordinating many other aspects of germ cell development and sex determination.

First, the 2 FBF proteins also bind to and block the translation of both fog- 1 [Thompson et al., 2005] and fog3 messages [Thompson et al., 2005; Kershner and Kimble, 2010; Snow et al., 2013]. Furthermore, $f b f-1$ and $f b f-2$ also interact with fog- 1 and fog- 3 to regulate cell proliferation, one of the other key choices facing germ cells [reviewed by Kimble and Crittenden, 2007].

Second, the PUF proteins play critical roles in the regulation of MAP kinase. In nematodes, genes of the MAP kinase (or ERK) pathway control many aspects of germline development [Church et al., 1995; Lee et al., 2007b]. One of these functions is promoting differentiation as spermatocytes rather than as oocytes [Lee et al., 2007b]. For example, some weak mutations in the MAP kinase gene $m p k-1$, or in other members of the pathway, lead all germ cells to differentiate as oocytes. Furthermore, strong mutations in these genes cause germ cells to arrest in the pachytene stage of meiosis I, and the arrested cells express oocyte transcripts, even in males. Finally, treat-

Sex Determination in Nematode Germ Cells ing puf-8; lip-1 mutants or $f b f-1$; lip-1 mutants with a MAP kinase inhibitor causes germ cells to develop as oocytes rather than as sperm [Morgan et al., 2010; Sorokin et al., 2014]. Genetic tests imply that MAP kinase acts near the end of the pathway to control sexual fates, but its targets are not known. However, the $m p k-1$ transcript itself has binding sites for FBF-1 and FBF-2 [Lee et al., 2007a], and the analysis of double mutants revealed that MAP kinase activity is redundantly controlled by these FBF proteins and the phosphatase LIP-1. Finally, MAP kinase targets the FBF partner NOS-3 in a feedback loop [Arur et al., 2011].

Third, the 2 FBF proteins bind to and regulate gld- 1 at its $3^{\prime}$-UTR [Crittenden et al., 2002]. This repression prevents GLD-1 from promoting entry into meiosis and from promoting male germ cell fates in developing hermaphrodites. Furthermore, the PUF proteins FBF-1 and PUF-8 regulate the expression of FOG-2, the partner of GLD-1 in activating hermaphrodite spermatogenesis [Bachorik and Kimble, 2005], although direct binding has not been shown.

Fourth, the FBF proteins also target one of the transcripts for $g l d-3$, which encodes a polyA polymerase subunit that promotes male germ cell fates [Eckmann et al., 2004]. Surprisingly, the GLD-3 and FBF proteins can bind each other [Eckmann et al., 2002], but the manner in which this interaction affects FBF activity remains unclear [Eckmann et al., 2002; Wu et al., 2013].

Thus, the FBF proteins, assisted at times by partners like PUF- 8 or NOS-3, block the translation of many genes needed for male germ cell fates in C. elegans (Fig. 3). However, they also regulate other aspects of germline development and interact with more than 1,000 known targets [Kershner and Kimble, 2010; Porter et al., 2019]. Their antagonism towards hermaphrodite spermatogenesis is not common to all nematode species, since some PUF proteins in C. briggsae promote spermatogenesis, instead of preventing it [Liu et al., 2012]. Instead, it seems likely that PUF proteins are central to germline development in all animals and have been recruited into the sperm/oocyte decision independently in different hermaphroditic species.

\section{Translational Regulation Maintains a Balance}

between TRA-2 and FEM-3 in C. elegans

As these results show, mutations that alter the expression of either fem-3 or tra-2 have dramatic effects on the hermaphrodite germ line. For example, fem-3 $(g f)$ animals make only sperm, whereas tra-2(gf) animals make only oocytes. Furthermore, tra-2(gf); fem-3(gf) double mu- 


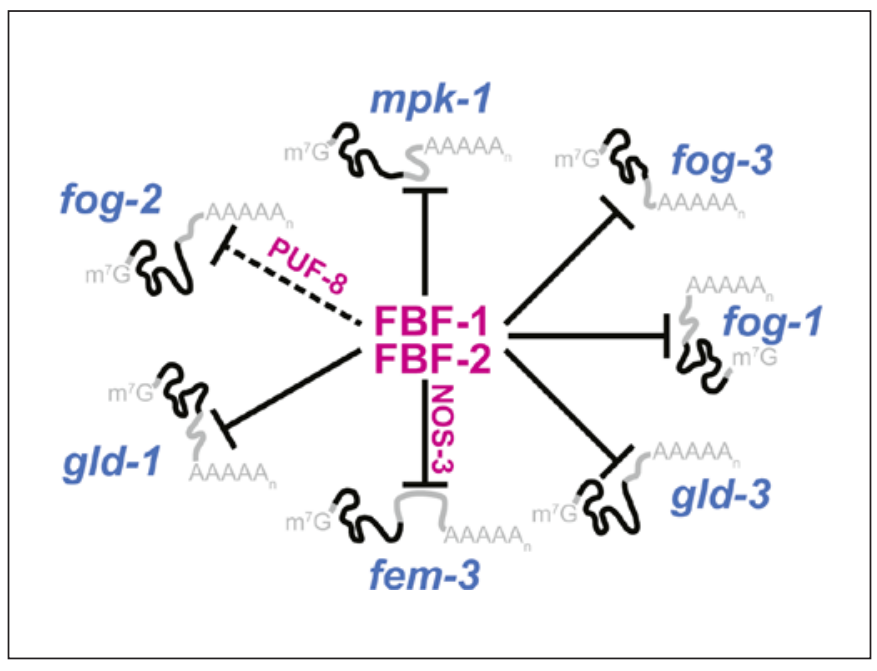

Fig. 3. The FBF proteins oppose male germ cell fates in C. elegans. Messenger RNAs that promote male fates are shaded blue, and proteins that promote female fates are shaded magenta. An inhibition arrow indicates negative regulation, with solid lines connoting direct interaction, and dotted lines connoting unknown interaction.

tants are restored to normal hermaphrodite development [Barton et al., 1987]. Thus, the balance between FEM-3 and TRA-2 levels might be critical for determining C. elegans germ cell fates.

Surprisingly, careful studies of TRA-2 protein expression show that the levels in the germ line are so low as to be barely detectable, despite the critical role that TRA-2 plays in this tissue [Hu et al., 2019]. Perhaps the evolution of hermaphrodites requires TRA-2 and FEM-3 expression to be reduced to low but similar levels, which can easily be pushed towards spermatogenesis or oogenesis by small changes in their relative levels.

Although this hypothesis can explain C. elegans germ cell fates, things must be different in $C$. briggsae, where fem-3 is not needed for spermatogenesis, and tra-2(null); fem-3(null) double mutants develop as normal hermaphrodites [Hill et al., 2006].

\section{Genes that Control RNA Processing and Metabolism Influence Germ Cell Fates}

Although translational regulators like the PUF proteins and GLD-1 play critical roles in determining germ cell fates in C. elegans, many other genes that control RNA processing, localization, or function also strongly influence the sperm/oocyte decision.

\section{Many Putative Splicing Factors Influence the} Expression of fem-3

The genes mog- 1 through mog- 6 were identified through mutations that cause XX animals to make only sperm, but do not affect XO animals [Graham and Kimble, 1993; Graham et al., 1993]. Although this phenotype is superficially similar to that of the $f e m-3(g f)$ mutants, there are a few important differences. First, the germ lines of these XX mutants appear less healthy than those of $f e m-3(g f)$ animals and contain fewer sperm. Second, if these mutants produce oocytes because of suppression by another sex-determining gene, the progeny all die, revealing a maternal effect for embryonic viability. Mutations in any of these 6 mog genes strongly affect the expression of a reporter gene carrying the fem-3 $3^{\prime}$-UTR in somatic tissues, which implies that they might encode components of the general translational machinery that are not restricted to the germ line [Gallegos et al., 1998]. Surprisingly, the fem-3(gf) mutations, which only affect germ cell fates, strongly upregulate this reporter in somatic tissues [Gallegos et al., 1998].

Molecular studies show that these MOG proteins are involved in RNA regulation. MOG- 1 contains a DEAH box and is homologous to PRP16 [Puoti and Kimble, 1999]. MOG-4 and MOG-5 are also DEAH-box proteins, related to PRP2 and PRP22, respectively [Puoti and Kimble, 2000]. All 3 PRP yeast proteins are involved in splicing. Furthermore, MOG-2 is a homolog of the spliceosomal protein $\mathrm{U}_{2} \mathrm{~A}^{\prime}$ and binds other components of the spliceosome [Zanetti et al., 2011]. MOG-3 is also homologous to spliceosome components [Kasturi et al., 2010], and MOG-6 is a cyclophilin [Belfiore et al., 2004]. Finally, yeast two-hybrid studies identified MEP-1 as a zinc-finger protein that binds MOG-1, MOG-3, MOG-4, MOG5, and MOG-6, as well as RNA [Belfiore et al., 2002, 2004; Kasturi et al., 2010], and studies using a reporter gene showed that mep- 1 is required for repression of the $\mathrm{fem}-3$ $3^{\prime}$-UTR [Belfiore et al., 2002]. Thus, these MOG proteins might work in a complex to regulate fem-3.

Over the years, many other genes have been found with this combination of phenotypes. For example, MAG1 is homologous to Drosophila Mago Nashi, and mag1(RNAi) mutants make only sperm, but produce dead embryos if a suppressor allows oogenesis [Li et al., 2000]. In addition, mutations in at $x$-2, the homolog of human ataxin-2, cause a Mog phenotype - many hermaphrodites make only sperm, but other germline processes are also affected, and embryos die [Maine et al., 2004]. ATX-2 binds the polyA binding protein and regulates translation in the germ line [Ciosk et al., 2004]. Furthermore, the trd-
10

Sex Dev

DOI: $10.1159 / 000520872$
Ellis 
1 gene, which encodes a tetratricopeptide-repeat protein, also has the classic Mog phenotype, as well as specific defects in larval development [Hughes et al., 2014]. And prp-17 mutants show all the classic Mog phenotypes [Kerins et al., 2010]. Since PRP-17 is a component of the splicing machinery, Kerins et al. [2010] did a general screen of splicing factors and found several additional ones that control the sperm/oocyte decision. Although homology suggests these mog genes should regulate splicing, there is no evidence of general splicing defects in mog- 1 or mog-6 mutants [Puoti and Kimble, 1999; Belfiore et al., 2004]. However, these general splicing assays are difficult in nematodes.

Finally, quantitative analyses of $f e m-3$ transcripts suggest that the $f e m-3(g f)$ alleles do not alter the efficiency of translation but instead increase the levels of transcripts that contain the $g f$ mutations [Zanetti et al., 2012]. Taking all these studies together, the PUF proteins might cooperate with a broad range of factors involved in RNA splicing to regulate mRNA stability. These splicing factors might directly participate in ribonucleoprotein complexes that regulate the stability or translation of $f e m-3$ transcripts. Alternatively, they might control the splicing of a sexdetermination transcript that is very sensitive to small changes in efficiency.

\section{LAF-1 and Other P Granule Components Regulate tra-2 Expression}

Mutations in laf- 1 show a complex set of phenotypes; they are dominant suppressors of the fem-3(gf) mutations but lethal when homozygous [Goodwin et al., 1997]. Furthermore, their effects on sex determination are not limited to germ cells but extend to somatic tissues in XO animals. All of these phenotypes are suppressed by tra-2 mutations, which implies that LAF-1 acts upstream of tra-2. Furthermore, laf-1 heterozygotes show elevated expression of reporter genes that contain the tra-2 $3^{\prime}$-UTR [Goodwin et al., 1997; Jan et al., 1997] and a mild increase in the levels of the TRA- $2_{\text {ic }}$ protein itself [Hubert and Anderson, 2009]. Thus, factors like LAF-1 might regulate tra-2 messages through their $3^{\prime}$-UTRs, in addition to the FOG-2/GLD-1 complex.

The LAF-1 protein is a DEAD-box helicase related to VBH-1 in worms, and Vasa and Belle in fruit flies [Hubert and Anderson, 2009]. VBH-1 works with LAF-1 to regulate germ cell fates, since more $v b h-1(R N A i)$; laf-1(RNAi) double mutants are female than occurs for either gene alone [Hubert and Anderson, 2009]. Although LAF-1 is expressed throughout the body and $\mathrm{VBH}-1$ only in the germ line, both proteins localize to $\mathrm{P}$ granules [Salinas et

Sex Determination in Nematode Germ Cells al., 2007; Hubert and Anderson, 2009]. These complex RNA/protein structures play a central role in RNA regulation in germ cells [reviewed by Voronina, 2013; Seydoux, 2018]. LAF-1 helps establish the phase separation that is needed to form the P granule "droplets" within the cell, and knocking down laf-1 by RNA interference eliminates these structures [Elbaum-Garfinkle et al., 2015].

Related components also influence sex determination in germ cells. For example, GLS-1 localizes to P granules, where it can bind GLD-3, releasing FBF and promoting the switch to oogenesis [Rybarska et al., 2009]. In addition, the eIF4E-transporter IFET-1 helps localize the translational regulators CGH-1 and CAR-1 to P granules [Sengupta et al., 2013], and double mutants between ifet1 and these genes make only sperm. Similarly, the eIF4E isoform IFE-3 also causes a Mog phenotype and acts upstream of $f e m-3$, although IFE-3 localizes to germ granules rather than the related $\mathrm{P}$ granules [Huggins et al., 2020]. Finally, MEL-46 influences sperm number, and mel-46 mutations weakly suppress fog-2 mutations [Minasaki et al., 2009]. Since MEL-46 is a DEAD-box helicase, it might also localize to $\mathrm{P}$ granules.

Thus, $\mathrm{P}$ granules play a complex role in the sperm/oocyte decision, since components like LAF-1 promote spermatogenesis, whereas others like IFET-1 promote oogenesis. An additional layer of complexity involves licensing of transcripts by the Argonaute protein CSR-1, which acts in $\mathrm{P}$ granules. Mutations in csr- 1 block P granule formation and cause a large increase in the transcription of genes needed for hermaphrodite spermatogenesis [Campbell and Updike, 2015].

\section{MicroRNA Regulation of Sexual Fates}

Although microRNAs play critical roles in the regulation of many aspects of development [reviewed by Galagali and Kim, 2020], they have been challenging to study, because they are often redundant and have broad, pleiotropic phenotypes.

The mir-35-42 microRNA family regulates several aspects of reproduction [McJunkin and Ambros, 2014]. One of these is the specification of sperm in hermaphrodites - a mir-35-42 deletion mutant makes fewer sperm than a wildtype hermaphrodite. Moreover, this effect is partially suppressed by mutations in sup-26, a predicted target of these microRNAs. SUP-26 itself influences sexdetermination by regulating the translation of tra-2 [Manser et al., 2002]. Surprisingly, it works in the soma to block translation of tra-2 messages, in a process that depends on the same target sequence that GLD-1 binds in the germ line [Mapes et al., 2010]. The mir-35-42 mi- 
croRNAs also influence sex-determination by regulating the DEAD-box helicase NHL-2 [McJunkin and Ambros, 2017]. Whether these genes also act in the germ line, or influence germ cell fates purely through their function in the soma, is unknown.

The mir-44 and mir-45 microRNAs belong to a different family that also controls hermaphrodite fertility [Maniates et al., 2021]. As with mir-35-42, the mutants make fewer sperm than normal. However, a mir-45 reporter is expressed in the hermaphrodite gonad where germ cells are deciding their fates, but not in the male gonad. Furthermore, mutations in mir-44 and mir-45 interact with other germline sex-determination mutations to control the number of sperm. Thus, this family is likely to act in germ cells themselves to control the sperm/oocyte decision.

Intriguingly, mutations in the PcG gene sop-2 cause hermaphrodites to make only sperm, and probably act by increasing the effectiveness of microRNA-mediated repression [Cai et al., 2008]. However, we do not know if this effect is mediated by the mir-35 or mir-44 families. And we do not yet know if the mir-35 family controls the sperm/oocyte decision by acting in germ cells or what messages mir- 45 targets in the germ line. Thus, the full story of microRNA regulation of germ cell fates is still being written.

Germ Cell Fates Are Extremely Sensitive to Changes in RNA Processing and Metabolism

Thus, many genes that influence RNA metabolism affect sexual fates in hermaphrodite germ cells. Three factors probably make hermaphrodites sensitive to changes in RNA metabolism. First, they face the complex task of switching quickly and accurately from making sperm to making oocytes. Second, they use several translational regulators, which act at many different regulatory points to control this cell fate decision. Third, there is a competitive balance between regulators promoting male germ cell fates and those promoting female fates, such as FEM3 versus TRA- 2 and GLD-2/GLD- 3 versus GLD-2/RPN8 . Thus, it is not surprising that this decision is exquisitely sensitive to regulatory changes in general RNA processing and control.

\section{Germ Cell Fate Regulation Changes Quickly during Evolution}

To date, most studies of how sex determination has evolved feature the related nematode $C$. briggsae, which also shares the advantages of hermaphrodite reproduc- tion. Fortunately, the 2 species developed self-fertility independently from a common male/female ancestor [Cho et al., 2004; Kiontke et al., 2004, 2011]. However, the components of the core sex-determination pathway remain the same in both, such as tra-1 [de Bono and Hodgkin, 1996; Kelleher et al., 2008], tra-2 [Kuwabara, 1996b; Kelleher et al., 2008], the fem genes [Hansen and Pilgrim, 1998; Hill et al., 2006], and fog-3 [Chen et al., 2001]. Although many of these proteins are evolving rapidly in sequence, they have preserved the same interaction partners, as seen for TRA-2/FEM-3 [Haag et al., 2002] and TRA-2/TRA-1 [Wang and Kimble, 2001].

However, the role of the fem genes differs significantly, since they are required for hermaphrodite spermatogenesis in C. elegans but not in C. briggsae [Hill et al., 2006]. The role of the TRR-1/Tip60 complex differs as well, since weak mutations prevent spermatogenesis in C. briggsae but not in C. elegans [Guo et al., 2013]. Furthermore, it appears that some translational modifiers of the pathway were recruited independently in these 2 species and as a result play very different roles [Beadell et al., 2011; Liu et al., 2012]. Finally, novel genes have been recruited to the pathway in each species [Nayak et al., 2005; Guo et al., 2009].

How have these changes come about? Nematodes appear to have certain features that simplify the evolution of self-fertile hermaphrodites [reviewed by Ellis and Lin, 2014]. These include an XX/XO chromosomal system of sex determination and a conveniently located sperm storage organ. As a result, self-fertility can be achieved with only a small number of genetic changes [Baldi et al., 2009]. Furthermore, nematodes are capable of passing through intermediate stages in which they produce 3 distinct sexes - XX females, XX hermaphrodites, and XO males - as observed in the new model worm Auanema rhodensis [Felix, 2004; Chaudhuri et al., 2011].

In Auanema, environmental cues not only control the pattern of larval development but also determine whether XX animals will develop female or hermaphrodite germ lines [Chaudhuri et al., 2011]. Animals raised in optimal conditions develop rapidly into females, whereas those that are starving develop via the dispersive dauer larval stage and become hermaphrodites. Hence, nutrition and other environmental cues can affect the sperm/ oocyte decision in this species. Surprisingly, meiosis in Auanema hermaphrodites has been modified to alter sex ratios in crosses with males [Tandonnet et al., 2018]. Thus, this species shows many differences not found in Caenorhabditis, highlighting the great plasticity of developmental regulation in germ cells.
12

Sex Dev

DOI: $10.1159 / 000520872$
Ellis 


\section{Conclusions}

Sex Determination Needs to Be Modified to Meet the Needs of Developing Germ Cells

Although nematodes use the same regulatory pathway to control sex determination in the soma and germ line, this pathway is highly modified in germ cells. These changes are critical because the germ line has unique functions: (1) Unlike the soma, germ cells need to decide between mitotic and meiotic patterns of cell division. Many of the regulators that influence this choice also play key roles in sex determination, like $f b f-1, f b f-2$, gld- 1 , fog-1, or fog-3. Thus, the 2 decisions might have to be linked [reviewed by Kimble and Page, 2007]. (2) XX animals need to provision oocytes with nutrients and messenger RNAs for the young embryo, which requires the extensive use of translational regulators and special structures like $\mathrm{P}$ granules to manage the transcripts. (3) Fidelity is critical, both to prevent errors in replication and to avoid the activation of transposons or genetic distorter elements. These needs require special systems for handling DNA and licensing gene expression. (4) The core pathway needs to be modified in self-fertile hermaphrodites to allow XX animals to make both sperm and oocytes.

As a result of these factors, the sex-determination process in germ cells shares many components with that in the soma but also has numerous modifications and unique features. This divergence is even more pronounced in fruit flies than in worms [reviewed by Salz and Erickson, 2010]. Furthermore, several genes that play other roles in the nematode germ line have been recruited to the sex-determination pathway in hermaphroditic species to regulate XX spermatogenesis and thus have different functions in C. elegans and C. briggsae, which evolved independently.

\section{Germ Cell Fates in Hermaphrodites Are Sensitive to Small Changes}

The developing germ cells of hermaphrodites are very sensitive to small regulatory changes so that some differentiating cells can accurately select one sex, while others can select the opposite one. During the fourth larval stage, this transition can be seen in a group of cells in the pachytene stage of meiosis I, with some differentiating as spermatocytes and adjacent ones as oocytes that are expressing yolk receptor mRNAs [Ellis and Schedl, 2007].

A major consequence of this sensitivity is that dozens and dozens of genes have mutations that alter sexual fate in the germ line. Although this profusion of regulators has been a challenge for the field, it also provides enormous opportunities. Identifying male or female germ cells is easy, both by microscopy and by testing for gene products like the major sperm protein in sperm or yolk receptor in oocytes. Thus, sex determination in the germ line provides a simple set of assays for studying a broad range of RNA biology and regulation in living animals.

\section{Competitive Regulatory Systems Ensure Fidelity and}

Rapid Decision Making

To ensure rapid and accurate regulatory changes, nematodes use sets of competing regulators in the germ line. In C. elegans, these include the closely balanced opposition of the core pathway proteins TRA-2 and FEM-3, as well as the antagonistic relationship between the GLD2/GLD-3 and GLD-2/RNP-8 polyA polymerases. This regulatory structure is designed to amplify changing signals very rapidly. It should help in the switch from spermatogenesis to oogenesis during hermaphrodite development and in maintaining stable sexual identity at other times.

\section{Translational Regulatory Networks Play a Central}

\section{Role in the Germ Line}

Translational regulators are critical for managing RNAs that will be packaged into oocytes [reviewed by Nousch and Eckmann, 2013]. As a result, they have come to play central roles in the control of all decisions in the germ line, including sex determination. For example, the STAR protein GLD-1, the large family of PUF proteins, their associated Nanos proteins, and the GLD2 polyA polymerase are all important parts of this process. These networks display extensive cross talk and feedback, which makes traditional pathway diagrams difficult. But they interact to produce self-reinforcing patterns of activity that specify mitosis, spermatogenesis, or oogenesis.

Furthermore, the key player in this final decision is the FOG-1/FOG-3 complex, a translational regulator composed of conserved proteins, whose mode of action is still being delineated. CPEB proteins play broad roles in germ cell development throughout the animal kingdom [reviewed by Ivshina et al., 2014]. For example, the fruit fly Orb protein, a CPEB protein like FOG-1, helps specify the oocyte fate, as opposed to the nurse cell fate [Barr et al., 2019]. And Tob/CPEB complexes are broadly conserved as well [White-Grindley et al., 2014]. However, the way the FOG-3/FOG-1 complex works, and the extent to which homologous structures control germ cell fates in other animals, remain to be determined. 


\section{Unanswered Questions}

Despite enormous progress in this field, which has revealed the structure of complex translational networks and identified numerous conserved regulators, much remains to be done. For example, in maturing hermaphrodites, germ cells switch from spermatogenesis to oogenesis while remaining part of a syncytium [Ellis and Schedl, 2007], but the nature of this switch is still a mystery [Ellis, 2008]. Furthermore, many of the key mechanistic details of sex determination are still largely or completely unknown. For example, how does FOG-2 work with the KH protein GLD-1 to regulate translation of tra-2? How does the FOG-1/FOG-3 complex block translation of target messages? Indeed, what other proteins act in this complex? And how do components of the splicing machinery influence cell fates through $\mathrm{fem}$-3? Fortunately, the recent ability to manipulate genes in their chromosomal context has revolutionized the field, so the next 20 years should be even more exciting than the last.

\section{Acknowledgements}

I would like to thank Judith Kimble and Eric Haag for valuable comments on this manuscript.

\section{Conflict of Interest Statement}

The author has no conflicts of interest to declare.

\section{Funding Sources}

I would like to thank the NIH for supporting this work through grants GM118836 and GM121688.

\section{References}

Ahringer J, Kimble J. Control of the sperm-oocyte switch in Caenorhabditis elegans hermaphrodites by the fem-3 3 ' untranslated region. $\mathrm{Na}-$ ture. 1991;349:346-8.

Ahringer J, Rosenquist TA, Lawson DN, Kimble J. The Caenorhabditis elegans sex determining gene $\mathrm{fem}-3$ is regulated post-transcriptionally. EMBO J. 1992;11:2303-10.

Aoki ST, Porter DF, Prasad A, Wickens M, Bingman CA, Kimble J. An RNA-Binding Multimer Specifies Nematode Sperm Fate. Cell Rep. 2018;23:3769-75.

Arur S, Ohmachi M, Berkseth M, Nayak S, Hansen D, Zarkower D, et al. MPK-1 ERK controls membrane organization in C. elegans oogenesis via a sex-determination module. Dev Cell. 2011;20:677-88.

Bachorik JL, Kimble J. Redundant control of the Caenorhabditis elegans sperm/oocyte switch by PUF- 8 and FBF-1, two distinct PUF RNAbinding proteins. Proc Natl Acad Sci U S A. 2005;102:10893-7.

Bachtrog D. Y-chromosome evolution: emerging insights into processes of Y-chromosome degeneration. Nat Rev Genet. 2013;14:113-24.

Baldi C, Cho S, Ellis RE. Mutations in two independent pathways are sufficient to create hermaphroditic nematodes. Science. 2009;326:1002-5.

Barnes TM, Hodgkin J. The tra-3 sex determination gene of Caenorhabditis elegans encodes a member of the calpain regulatory protease family. EMBO J. 1996;15:4477-84.

Barr J, Gilmutdinov R, Wang L, Shidlovskii Y, Schedl P. The Drosophila CPEB Protein Orb Specifies Oocyte Fate by a 3'UTR-Dependent Autoregulatory Loop. Genetics. 2019;213: 1431-46.
Barton MK, Kimble J. fog-1, a regulatory gene required for specification of spermatogenesis in the germ line of Caenorhabditis elegans. Genetics. 1990;125:29-39.

Barton MK, Schedl TB, Kimble J. Gain-of-function mutations of $f e m-3$, a sex-determination gene in Caenorhabditis elegans. Genetics. 1987;115:107-19.

Beadell AV, Liu Q, Johnson DM, Haag ES. Independent recruitments of a translational regulator in the evolution of self-fertile nematodes. Proc Natl Acad Sci U S A. 2011;108:19672-7.

Belfiore M, Mathies LD, Pugnale P, Moulder G, Barstead R, Kimble J, et al. The MEP-1 zincfinger protein acts with MOG DEAH box proteins to control gene expression via the fem-3 3' untranslated region in Caenorhabditis elegans. RNA. 2002;8:725-39.

Belfiore M, Pugnale P, Saudan Z, Puoti A. Roles of the C. elegans cyclophilin-like protein MOG-6 in MEP-1 binding and germline fates. Development. 2004;131:2935-45.

Berkseth M, Ikegami K, Arur S, Lieb JD, Zarkower D. TRA-1 ChIP-seq reveals regulators of sexual differentiation and multilevel feedback in nematode sex determination. Proc Natl Acad Sci U S A. 2013;110:16033-8.

Brenner S. The genetics of Caenorhabditis elegans. Genetics. 1974;77(1):71-94.

Burglin TR, Kuwabara PE. Homologs of the Hh signalling network in C. elegans. WormBook. 2006;1-14.

Cai Q, Sun Y, Huang X, Guo C, Zhang Y, Zhu Z, et al. The Caenorhabditis elegans PcG-like gene sop-2 regulates the temporal and sexual specificities of cell fates. Genetics. 2008;178: 1445-56.
Campbell AC, Updike DL. CSR-1 and P granules suppress sperm-specific transcription in the C. elegans germline. Development. 2015;142: 1745-55.

Cavalier-Smith T. Origin of animal multicellularity: precursors, causes, consequences-the choanoflagellate/sponge transition, neurogenesis and the Cambrian explosion. Philos Trans R Soc Lond B Biol Sci. 2017;372: 20150476.

Chaudhuri J, Kache V, Pires-daSilva A. Regulation of sexual plasticity in a nematode that produces males, females, and hermaphrodites. Curr Biol. 2011;21:1548-51.

Chen P, Ellis RE. TRA-1A regulates transcription of $f \circ g$ - 3 , which controls germ cell fate in $C$. elegans. Development. 2000;127:3119-29.

Chen PJ, Singal A, Kimble J, Ellis RE. A novel member of the tob family of proteins controls sexual fate in Caenorhabditis elegans germ cells. Dev Biol. 2000;217:77-90.

Chen PJ, Cho S, Jin SW, Ellis RE. Specification of germ cell fates by FOG-3 has been conserved during nematode evolution. Genetics. 2001; 158:1513-25.

Chen X, Shen Y, Ellis RE. Dependence of the sperm/oocyte decision on the Nucleosome Remodeling Factor Complex was acquired during recent Caenorhabditis briggsae evolution. Mol Biol Evol. 2014;31:2573-85.

Chin-Sang ID, Spence AM. Caenorhabditis elegans sex-determining protein FEM-2 is a protein phosphatase that promotes male development and interacts directly with FEM-3. Genes Dev. 1996;10:2314-25. 
Cho S, Jin SW, Cohen A, Ellis RE. A phylogeny of Caenorhabditis reveals frequent loss of introns during nematode evolution. Genome Res. 2004;14:1207-20.

Cho S, Rogers KW, Fay DS. The C. elegans glycopeptide hormone receptor ortholog, FSHR-1, regulates germline differentiation and survival. Curr Biol. 2007;17:203-12.

Chu DS, Dawes HE, Lieb JD, Chan RC, Kuo AF, Meyer BJ. A molecular link between genespecific and chromosome-wide transcriptional repression. Genes Dev. 2002;16:796805.

Church DL, Guan KL, Lambie EJ. Three genes of the MAP kinase cascade, mek-2, mpk-1/sur-1 and let-60 ras, are required for meiotic cell cycle progression in Caenorhabditis elegans. Development. 1995;121:2525-35.

Ciosk R, DePalma M, Priess JR. ATX-2, the C. elegans ortholog of ataxin 2, functions in translational regulation in the germline. Development. 2004;131:4831-41.

Clifford R, Lee MH, Nayak S, Ohmachi M, Giorgini F, Schedl T. FOG-2, a novel F-box containing protein, associates with the GLD-1 RNA binding protein and directs male sex determination in the C. elegans hermaphrodite germline. Development. 2000;127:5265-76.

Crittenden SL, Bernstein DS, Bachorik JL, Thompson BE, Gallegos M, Petcherski AG, et al. A conserved RNA-binding protein controls germline stem cells in Caenorhabditis elegans. Nature. 2002;417:660-3.

de Bono M, Hodgkin J. Evolution of sex determination in Caenorhabditis: unusually high divergence of tra-1 and its functional consequences. Genetics. 1996;144:587-95.

de Bono M, Zarkower D, Hodgkin J. Dominant feminizing mutations implicate protein-protein interactions as the main mode of regulation of the nematode sex-determining gene tra-1. Genes Dev. 1995;9:155-67.

del Castillo-Olivares A, Kulkarni M, Smith HE. Regulation of sperm gene expression by the GATA factor ELT-1. Dev Biol. 2009;333:397408.

Doniach T. Activity of the sex-determining gene tra-2 is modulated to allow spermatogenesis in the C. elegans hermaphrodite. Genetics. 1986;114:53-76.

Eckmann CR, Kraemer B, Wickens M, Kimble J. GLD-3, a bicaudal-C homolog that inhibits FBF to control germline sex determination in C. elegans. Dev Cell. 2002;3:697-710.

Eckmann CR, Crittenden SL, Suh N, Kimble J. GLD-3 and control of the mitosis/meiosis decision in the germline of Caenorhabditis elegans. Genetics. 2004;168:147-60.

Elbaum-Garfinkle S, Kim Y, Szczepaniak K, Chen CC, Eckmann CR, Myong S, et al. The disordered $\mathrm{P}$ granule protein LAF-1 drives phase separation into droplets with tunable viscosity and dynamics. Proc Natl Acad Sci U S A. 2015;112:7189-94.

Ellis RE. Sex determination in the Caenorhabditis elegans germ line. Curr Top Dev Biol. 2008; 83:41-64.
Ellis RE, Kimble J. The fog-3 gene and regulation of cell fate in the germ line of Caenorhabditis elegans. Genetics. 1995;139:561-77.

Ellis RE, Schedl T. Sex-determination in the germ line. WormBook. 2007;1-13.

Ellis RE, Lin SY. The evolutionary origins and consequences of self-fertility in nematodes. F1000Prime Rep. 2014;6:62.

Ellis RE, Stanfield GM. The regulation of spermatogenesis and sperm function in nematodes. Semin Cell Dev Biol. 2014;29:17-30.

Extavour CG, Akam M. Mechanisms of germ cell specification across the metazoans: epigenesis and preformation. Development. 2003;130: 5869-84.

Farboud B, Nix P, Jow MM, Gladden JM, Meyer BJ. Molecular antagonism between X-chromosome and autosome signals determines nematode sex. Genes Dev. 2013;27:1159-78.

Felix MA. Alternative morphs and plasticity of vulval development in a rhabditid nematode species. Dev Genes Evol. 2004;214:55-63.

Fernando LM, Elliot J, Allen AK. The Caenorhabditis elegans proteasome subunit RPN-12 is required for hermaphrodite germline sex determination and oocyte quality. Dev Dyn. 2021;250(2):145-59.

Francis R, Barton MK, Kimble J, Schedl T. gld-1, a tumor suppressor gene required for oocyte development in Caenorhabditis elegans. Genetics. 1995a;139:579-606.

Francis R, Maine E, Schedl T. Analysis of the multiple roles of gld-1 in germline development: interactions with the sex determination cascade and the $g l p-1$ signaling pathway. Genetics. 1995b;139:607-30.

Galagali H, Kim JK. The multifaceted roles of microRNAs in differentiation. Curr Opin Cell Biol. 2020;67:118-40.

Gallegos M, Ahringer J, Crittenden S, Kimble J. Repression by the 3' UTR of fem-3, a sex-determining gene, relies on a ubiquitous mogdependent control in Caenorhabditis elegans. EMBO J. 1998;17:6337-47.

Gartner A, Boag PR, Blackwell TK. Germline survival and apoptosis. WormBook. 2008;1-20.

Geng S, De Hoff P, Umen JG. Evolution of sexes from an ancestral mating-type specification pathway. PLoS Biol. 2014;12:e1001904.

Goodwin EB, Hofstra K, Hurney CA, Mango S, Kimble J. A genetic pathway for regulation of tra-2 translation. Development. 1997;124: 749-58.

Goodwin EB, Okkema PG, Evans TC, Kimble J. Translational regulation of tra- 2 by its 3 ' untranslated region controls sexual identity in $C$. elegans. Cell. 1993;75:329-39.

Gordon KL, Zussman JW, Li X, Miller C, Sherwood DR. Stem cell niche exit in C. elegans via orientation and segregation of daughter cells by a cryptic cell outside the niche. Elife. 2020; 9:e56383.

Graham PL, Kimble J. The mog-1 gene is required for the switch from spermatogenesis to oogenesis in Caenorhabditis elegans. Genetics. 1993;133:919-31.
Graham PL, Schedl T, Kimble J. More mog genes that influence the switch from spermatogenesis to oogenesis in the hermaphrodite germ line of Caenorhabditis elegans. Dev Genet. 1993;14:471-84.

Guo Y, Lang S, Ellis RE. Independent recruitment of $\mathrm{F}$ box genes to regulate hermaphrodite development during nematode evolution. Curr Biol. 2009; 19:1853-60.

Guo Y, Chen X, Ellis RE. Evolutionary change within a bipotential switch shaped the sperm/ oocyte decision in hermaphroditic nematodes. PLoS Genet. 2013;9:e1003850.

Haag ES, Wang S, Kimble J. Rapid coevolution of the nematode sex-determining genes fem-3 and tra-2. Curr Biol. 2002;12:2035-41.

Hansen D, Pilgrim D. Molecular evolution of a sex determination protein. FEM-2 (pp2c) in Caenorhabditis. Genetics. 1998;149:1353-62.

Hill RC, Haag ES. A sensitized genetic background reveals evolution near the terminus of the Caenorhabditis germline sex determination pathway. Evol Dev. 2009;11:333-42.

Hill RC, de Carvalho CE, Salogiannis J, Schlager B, Pilgrim D, Haag ES. Genetic flexibility in the convergent evolution of hermaphroditism in Caenorhabditis nematodes. Dev Cell. 2006; 10:531-8.

Hodgkin J. More sex-determination mutants of Caenorhabditis elegans. Genetics. 1980;96: 649-64.

Hodgkin J. Sex determination in the nematode $C$. elegans: analysis of tra-3 suppressors and characterization of fem genes. Genetics. 1986; 114:15-52

Hodgkin J. A genetic analysis of the sex-determining gene, tra-1, in the nematode Caenorhabditis elegans. Genes Dev. 1987;1:731-45.

Hodgkin JA, Brenner S. Mutations causing transformation of sexual phenotype in the nematode Caenorhabditis elegans. Genetics. 1977; 86:275-87.

Hu S, Skelly LE, Kaymak E, Freeberg L, Lo TW, Kuersten S, et al. Multi-modal regulation of $C$. elegans hermaphrodite spermatogenesis by the GLD-1-FOG-2 complex. Dev Biol. 2019; 446:193-205.

Hubert A, Anderson P. The C. elegans sex determination gene laf- 1 encodes a putative DEADbox RNA helicase. Dev Biol. 2009;330:358-67.

Huelgas-Morales G, Greenstein D. Control of oocyte meiotic maturation in C. elegans. Semin Cell Dev Biol. 2018;84:90-9.

Huggins HP, Subash JS, Stoffel H, Henderson MA, Hoffman JL, Buckner DS, et al. Distinct roles of two eIF4E isoforms in the germline of Caenorhabditis elegans. J Cell Sci. 2020;133: jcs237990.

Hughes S, Wilkinson H, Gilbert SP, Kishida M, Ding SS, Woollard A. The C. elegans TPR Containing Protein, TRD-1, Regulates Cell Fate Choice in the Developing Germ Line and Epidermis. PLoS One. 2014;9:e114998.

Hunter CP, Wood WB. Evidence from mosaic analysis of the masculinizing gene her-1 for cell interactions in C. elegans sex determination. Nature. 1992;355:551-5. 
Ivshina M, Lasko P, Richter JD. Cytoplasmic polyadenylation element binding proteins in development, health, and disease. Annu Rev Cell Dev Biol. 2014;30:393-415.

Jan E, Motzny CK, Graves LE, Goodwin EB. The STAR protein, GLD-1, is a translational regulator of sexual identity in Caenorhabditis elegans. EMBO J. 1999;18:258-69.

Jan E, Yoon JW, Walterhouse D, Iannaccone P, Goodwin EB. Conservation of the C.elegans tra-2 3'UTR translational control. EMBO J. 1997; 16:6301-13.

Jin SW, Arno N, Cohen A, Shah A, Xu Q, Chen $\mathrm{N}$, et al. In Caenorhabditis elegans, the RNAbinding domains of the cytoplasmic polyadenylation element binding protein FOG-1 are needed to regulate germ cell fates. Genetics. 2001a;159:1617-30.

Jin SW, Kimble J, Ellis RE. Regulation of cell fate in Caenorhabditis elegans by a novel cytoplasmic polyadenylation element binding protein. Dev Biol. 2001b;229:537-53.

Jones AR, Schedl T. Mutations in gld-1, a female germ cell-specific tumor suppressor gene in Caenorhabditis elegans, affect a conserved domain also found in Src-associated protein Sam68. Genes Dev. 1995;9:1491-504.

Jones AR, Francis R, Schedl T. GLD-1, a cytoplasmic protein essential for oocyte differentiation, shows stage- and sex-specific expression during Caenorhabditis elegans germline development. Dev Biol. 1996;180:165-83.

Kadyk LC, Kimble J. Genetic regulation of entry into meiosis in Caenorhabditis elegans. Development. 1998;125:1803-13.

Kasturi P, Zanetti S, Passannante M, Saudan Z, Müller F, Puoti A. The C. elegans sex determination protein MOG-3 functions in meiosis and binds to the CSL co-repressor CIR-1. Dev Biol. 2010;344:593-602.

Kelleher DF, de Carvalho CE, Doty AV, Layton $\mathrm{M}$, Cheng AT, Mathies LD, et al. Comparative genetics of sex determination: masculinizing mutations in Caenorhabditis briggsae. Genetics. 2008;178:1415-29.

Kerins JA, Hanazawa M, Dorsett M, Schedl T. PRP-17 and the pre-mRNA splicing pathway are preferentially required for the proliferation versus meiotic development decision and germline sex determination in Caenorhabditis elegans. Dev Dyn. 2010;239:1555-72.

Kershner AM, Kimble J. Genome-wide analysis of mRNA targets for Caenorhabditis elegans FBF, a conserved stem cell regulator. Proc Natl Acad Sci U S A. 2010;107:3936-41.

Kim KW, Nykamp K, Suh N, Bachorik JL, Wang L, Kimble J. Antagonism between GLD-2 binding partners controls gamete sex. Dev Cell. 2009;16:723-33.

Kim S, Govindan JA, Tu ZJ, Greenstein D. SACY1 DEAD-Box helicase links the somatic control of oocyte meiotic maturation to the sperm-to-oocyte switch and gamete maintenance in Caenorhabditis elegans. Genetics. 2012;192:905-28.
Kimble J, Crittenden SL. Controls of germline stem cells, entry into meiosis, and the sperm/ oocyte decision in Caenorhabditis elegans. Annu Rev Cell Dev Biol. 2007;23:405-33.

Kimble J, Hirsh D. The postembryonic cell lineages of the hermaphrodite and male gonads in Caenorhabditis elegans. Dev Biol. 1979;70: 396-417.

Kimble J, Page DC. The mysteries of sexual identity. The germ cell's perspective. Science. 2007;316:400-1.

Kimble JE, White JG. On the control of germ cell development in Caenorhabditis elegans. Dev Biol. 1981;81:208-19.

Kimble J, Edgar L, Hirsh D. Specification of male development in Caenorhabditis elegans: the fem genes. Dev Biol. 1984;105:234-9.

Kiontke K, Gavin NP, Raynes Y, Roehrig C, Piano F, Fitch DH. Caenorhabditis phylogeny predicts convergence of hermaphroditism and extensive intron loss. Proc Natl Acad Sci U S A. 2004;101:9003-8.

Kiontke KC, Félix MA, Ailion M, Rockman MV, Braendle C, Pénigault JB, et al. A phylogeny and molecular barcodes for Caenorhabditis, with numerous new species from rotting fruits. BMC Evol Biol. 2011;11:339.

Kirk DL. A twelve-step program for evolving multicellularity and a division of labor. Bioessays. 2005;27:299-310.

Kraemer B, Crittenden S, Gallegos M, Moulder G, Barstead R, Kimble J, et al. NANOS-3 and FBF proteins physically interact to control the sperm-oocyte switch in Caenorhabditis elegans. Curr Biol. 1999;9:1009-18.

Kulkarni M, Shakes DC, Guevel K, Smith HE, SPE-44 implements sperm cell fate. PLoS Genet. 2012;8:e1002678.

Kuwabara PE. A novel regulatory mutation in the C. elegans sex determination gene tra-2 defines a candidate ligand/receptor interaction site. Development. 1996a;122:2089-98.

Kuwabara PE. Interspecies comparison reveals evolution of control regions in the nematode sex-determining gene tra-2. Genetics. 1996b; 144:597-607.

Kuwabara PE, Kimble J. A predicted membrane protein, TRA-2A, directs hermaphrodite development in Caenorhabditis elegans. Development. 1995;121:2995-3004.

Kuwabara PE, Okkema PG, Kimble J. tra-2 encodes a membrane protein and may mediate cell communication in the Caenorhabditis elegans sex determination pathway. Mol Biol Cell. 1992;3:461-73.

Kuwabara PE, Okkema PG, Kimble J. Germ-line regulation of the Caenorhabditis elegans sexdetermining gene tra-2. Dev Biol. 1998;204: 251-62.

Lamont LB, Kimble J. Developmental expression of FOG-1/CPEB protein and its control in the Caenorhabditis elegans hermaphrodite germ line. Dev Dyn. 2007;236:871-9.

Lee MH, Schedl T. Identification of in vivo mRNA targets of GLD-1, a maxi-KH motif containing protein required for C. elegans germ cell development. Genes Dev. 2001;15:2408-20.
Lee MH, Schedl T. Translation repression by GLD-1 protects its mRNA targets from nonsense-mediated mRNA decay in C. elegans. Genes Dev. 2004;18:1047-59.

Lee MH, Hook B, Pan G, Kershner AM, Merritt C, Seydoux G, et al. Conserved regulation of MAP kinase expression by PUF RNA-binding proteins. PLoS Genet. 2007a;3:e233.

Lee MH, Ohmachi M, Arur S, Nayak S, Francis R, Church D, et al. Multiple functions and dynamic activation of MPK-1 extracellular signal-regulated kinase signaling in Caenorhabditis elegans germline development. Genetics. 2007b;177:2039-62.

Lee MH, Kim KW, Morgan CT, Morgan DE, Kimble J. Phosphorylation state of a Tob/ BTG protein, FOG-3, regulates initiation and maintenance of the Caenorhabditis elegans sperm fate program. Proc Natl Acad Sci U S A. 2011;108:9125-30.

Li T, Kelly WG. A role for Set1/MLL-related components in epigenetic regulation of the Caenorhabditis elegans germ line. PLoS Genet. 2011;7:e1001349.

Li T, Kelly WG. A role for WDR5 in TRA-1/Gli mediated transcriptional control of the sperm/oocyte switch in C. elegans. Nucleic Acids Res. 2014;42:5567-81.

Li W, Boswell R, Wood WB. mag-1, a homolog of Drosophila mago nashi, regulates hermaphrodite germ-line sex determination in Caenorhabditis elegans. Dev Biol. 2000;218:172-82.

Liu Q, Stumpf C, Thomas C, Wickens M, Haag ES. Context-dependent function of a conserved translational regulatory module. Development. 2012;139:1509-21.

Luitjens C, Gallegos M, Kraemer B, Kimble J, Wickens M. CPEB proteins control two key steps in spermatogenesis in C. elegans. Genes Dev. 2000;14:2596-609.

Lum DH, Kuwabara PE, Zarkower D, Spence AM. Direct protein-protein interaction between the intracellular domain of TRA- 2 and the transcription factor TRA-1A modulates feminizing activity in C. elegans. Genes Dev. 2000; 14:3153-65.

Madl JE, Herman RK. Polyploids and sex determination in Caenorhabditis elegans. Genetics. 1979;93:393-402.

Maine EM, Hansen D, Springer D, Vought VE. Caenorhabditis elegans atx- 2 promotes germline proliferation and the oocyte fate. Genetics. 2004;168:817-30.

Maniates KA, Olson BS, Abbott AL. Sperm fate is promoted by the mir-44 microRNA family in the Caenorhabditis elegans hermaphrodite germline. Genetics. 2021;217(1):1-14.

Manser J, Wood WB, Perry MD. Extragenic suppressors of a dominant masculinizing her-1 mutation in C. elegans identify two new genes that affect sex determination in different ways. Genesis. 2002;34:184-95.

Mapes J, Chen JT, Yu JS, Xue D. Somatic sex determination in Caenorhabditis elegans is modulated by SUP-26 repression of tra-2 translation. Proc Natl Acad Sci U S A. 2010; 107:18022-7. 
Maupas E. Modes et formes de reproduction des nematodes. Arch Zool Exp Gen. 1900;8:463624.

Mauxion F, Chen CY, Séraphin B, Shyu AB. BTG/ TOB factors impact deadenylases. Trends Biochem Sci. 2009;34:640-7.

McCarter J, Bartlett B, Dang T, Schedl T. Somagerm cell interactions in Caenorhabditis elegans: multiple events of hermaphrodite germline development require the somatic sheath and spermathecal lineages. Dev Biol. 1997; 181:121-43.

McJunkin K, Ambros V. The embryonic mir-35 family of microRNAs promotes multiple aspects of fecundity in Caenorhabditis elegans. G3 (Bethesda). 2014;4:1747-54.

McJunkin K, Ambros V. A microRNA family exerts maternal control on sex determination in C. elegans. Genes Dev. 2017;31:422-37.

Mehra A, Gaudet J, Heck L, Kuwabara PE, Spence AM. Negative regulation of male development in Caenorhabditis elegans by a proteinprotein interaction between TRA-2A and FEM-3. Genes Dev. 1999;13:1453-63.

Merritt C, Rasoloson D, Ko D, Seydoux G. 3 UTRs are the primary regulators of gene expression in the C. elegans germline. Curr Biol. 2008; 18:1476-82.

Minasaki R, Puoti A, Streit A. The DEAD-box protein MEL-46 is required in the germ line of the nematode Caenorhabditis elegans. BMC Dev Biol. 2009;9:35.

Molin L, Puisieux A. C. elegans homologue of the Cafl gene, which encodes a subunit of the CCR4-NOT complex, is essential for embryonic and larval development and for meiotic progression. Gene. 2005;358:73-81.

Morgan CT, Lee MH, Kimble J. Chemical reprogramming of Caenorhabditis elegans germ cell fate. Nat Chem Biol. 2010;6:102-4.

Nagy LG, Kovács GM, Krizsán K. Complex multicellularity in fungi: evolutionary convergence, single origin, or both. Biol Rev Camb Philos Soc. 2018;93:1778-94.

Nayak S, Goree J, Schedl T. fog-2 and the evolution of self-fertile hermaphroditism in Caenorhabditis. PLoS Biol. 2005;3:e6.

Newmark PA, Wang Y, Chong T. Germ cell specification and regeneration in planarians. Cold Spring Harb Symp Quant Biol. 2008;73:57381.

Nigon V. Les modalités de la réproduction et le déterminisme de sexe chez quelques Nématodes libres. Ann Sci Nat Zool. 1949;11:1-132.

Noble DC, Aoki ST, Ortiz MA, Kim KW, Verheyden JM, Kimble J. Genomic Analyses of Sperm Fate Regulator Targets Reveal a Common Set of Oogenic mRNAs in Caenorhabditis elegans. Genetics. 2016;202:221-34.

Nousch M, Eckmann CR. Translational control in the Caenorhabditis elegans germ line. Adv Exp Med Biol. 2013;757:205-47.

Nousch M, Techritz N, Hampel D, Millonigg S, Eckmann CR. The Ccr4-Not deadenylase complex constitutes the main poly $(\mathrm{A})$ removal activity in C. elegans. J Cell Sci. 2013;126: 4274-85.
Nykamp K, Lee MH, Kimble J. C. elegans Larelated protein, LARP-1, localizes to germline $\mathrm{P}$ bodies and attenuates Ras-MAPK signaling during oogenesis. RNA. 2008; 14: 1378-89.

Okkema PG, Kimble J. Molecular analysis of tra2, a sex determining gene in C.elegans. EMBO J. 1991;10:171-6.

Ortiz MA, Noble D, Sorokin EP, Kimble J. A new dataset of spermatogenic vs. oogenic transcriptomes in the nematode Caenorhabditis elegans. G3 (Bethesda). 2014;4:1765-72.

Parker GA, Baker RR, Smith VG. The origin and evolution of gamete dimorphism and the male-female phenomenon. J Theor Biol. 1972;36:529-53.

Pereira PA, Navarro-Costa P, Martinho RG Becker JD. Evolutionarily conserved mechanisms of male germline development in flowering plants and animals. Biochem Soc Trans. 2014;42:377-82.

Porter DF, Prasad A, Carrick BH, Kroll-Connor P, Wickens M, Kimble J. Toward Identifying Subnetworks from FBF Binding Landscapes in Caenorhabditis Spermatogenic or Oogenic Germlines. G3 (Bethesda). 2019;9:153-65

Puoti A, Kimble J. The Caenorhabditis elegans sex determination gene $\operatorname{mog}-1$ encodes a member of the DEAH-Box protein family. Mol Cell Biol. 1999;19:2189-97.

Puoti A, Kimble J. The hermaphrodite sperm/oocyte switch requires the Caenorhabditis elegans homologs of PRP2 and PRP22. Proc Natl Acad Sci U S A. 2000;97:3276-81.

Ragle JM, Aita AL, Morrison KN, Martinez-Mendez R, Saeger HN, Ashley GA, et al. The conserved molting/circadian rhythm regulator NHR-23/NR1F1 serves as an essential co-regulator of C. elegans spermatogenesis. Development. 2020;147.

Rashid S, Wong C, Roy R. Developmental plasticity and the response to nutrient stress in $\mathrm{Cae}$ norhabditis elegans. Dev Biol. 2021;475:26576.

Reinke V, Smith HE, Nance J, Wang J, Van Doren C, Begley R, et al. A global profile of germline gene expression in C. elegans. Mol Cell. 2000; 6:605-16.

Reinke V, Gil IS, Ward S, Kazmer K. Genomewide germline-enriched and sex-biased expression profiles in Caenorhabditis elegans. Development. 2004;131:311-23.

Rybarska A, Harterink M, Jedamzik B, Kupinski AP, Schmid M, Eckmann CR. GLS-1, a novel $\mathrm{P}$ granule component, modulates a network of conserved RNA regulators to influence germ cell fate decisions. PLoS Genet. 2009;5: e1000494.

Ryder SP, Frater LA, Abramovitz DL, Goodwin EB, Williamson JR. RNA target specificity of the STAR/GSG domain post-transcriptional regulatory protein GLD-1. Nat Struct $\mathrm{Mol}$ Biol. 2004;11:20-8.

Salinas LS, Maldonado E, Macías-Silva M, Blackwell TK, Navarro RE. The DEAD box RNA helicase VBH-1 is required for germ cell function in C. elegans. Genesis. 2007;45:533-46.
Salz HK, Erickson JW. Sex determination in Drosophila: The view from the top. Fly (Austin). 2010;4:60-70.

Sasagawa Y, Otani M, Higashitani N, Higashitani A, Sato K, Ogura T, et al. Caenorhabditis elegans $\mathrm{p} 97$ controls germline-specific sex determination by controlling the TRA-1 level in a CUL-2-dependent manner. J Cell Sci. 2009; 122:3663-72.

Sasagawa Y, Yamanaka K, Saito-Sasagawa Y, Ogura T. Caenorhabditis elegans UBX cofactors for CDC-48/p97 control spermatogenesis. Genes Cells. 2010;15:1201-15.

Scheckel C, Gaidatzis D, Wright JE, Ciosk R. Genome-wide analysis of GLD-1-mediated mRNA regulation suggests a role in mRNA storage. PLoS Genet. 2012;8:e1002742.

Schedl T, Kimble J. fog-2, a germ-line-specific sex determination gene required for hermaphrodite spermatogenesis in Caenorhabditis elegans. Genetics. 1988;119:43-61.

Schedl T, Graham PL, Barton MK, Kimble J. Analysis of the role of tra-1 in germline sex determination in the nematode Caenorhabditis elegans. Genetics. 1989;123:755-69.

Schvarzstein M, Spence AM. The C. elegans sexdetermining GLI protein TRA-1A is regulated by sex-specific proteolysis. Dev Cell. 2006; 11:733-40.

Sengupta MS, Low WY, Patterson JR, Kim HM, Traven A, Beilharz TH, et al. ifet-1 is a broadscale translational repressor required for normal P granule formation in C. elegans. J Cell Sci. 2013;126:850-9.

Seydoux G. The P Granules of C. elegans: A Genetic Model for the Study of RNA-Protein Condensates. J Mol Biol. 2018;430:4702-10.

Shim YH. elt-1, a gene encoding a Caenorhabditis elegans GATA transcription factor, is highly expressed in the germ lines with msp genes as the potential targets. Mol Cells. 1999;9:535-41.

Shimada M, Kanematsu K, Tanaka K, Yokosawa $\mathrm{H}$, Kawahara H. Proteasomal ubiquitin receptor RPN-10 controls sex determination in Caenorhabditis elegans. Mol Biol Cell. 2006; 17:5356-71.

Snow JJ, Lee MH, Verheyden J, Kroll-Conner PL, Kimble J. C. elegans FOG-3/Tob can either promote or inhibit germline proliferation, depending on gene dosage and genetic context. Oncogene. 2013;32:2614-21.

Sokol SB, Kuwabara PE. Proteolysis in Caenorhabditis elegans sex determination: cleavage of TRA-2A by TRA-3. Genes Dev. 2000;14:901-6.

Sonoda J, Wharton RP. Recruitment of Nanos to hunchback mRNA by Pumilio. Genes Dev. 1999;13:2704-12.

Sorokin EP, Gasch AP, Kimble J. Competence for chemical reprogramming of sexual fate correlates with an intersexual molecular signature in Caenorhabditis elegans. Genetics. 2014;198:561-75.

Spence AM, Coulson A, Hodgkin J. The product of fem-1, a nematode sex-determining gene, contains a motif found in cell cycle control proteins and receptors for cell-cell interactions. Cell. 1990;60:981-90.
Sex Determination in Nematode Germ Cells
Sex Dev 
Starostina NG, Lim JM, Schvarzstein M, Wells L, Spence AM, Kipreos ET. A CUL-2 ubiquitin ligase containing three FEM proteins degrades TRA- 1 to regulate C. elegans sex determination. Dev Cell. 2007;13:127-39.

Tandonnet S, Farrell MC, Koutsovoulos GD, Blaxter ML, Parihar M, Sadler PL, et al. Sexand Gamete-Specific Patterns of X Chromosome Segregation in a Trioecious Nematode. Curr Biol. 2018;28:93e3-e3.

Thompson BE, Bernstein DS, Bachorik JL, Petcherski AG, Wickens M, Kimble J. Dose-dependent control of proliferation and sperm specification by FOG-1/CPEB. Development. 2005; 132:3471-81.

Trent C, Purnell B, Gavinski S, Hageman J, Chamblin C, Wood WB. Sex-specific transcriptional regulation of the $C$. elegans sex-determining gene her-1. Mech Dev. 1991;34:43-55.

Tzur YB, Winter E, Gao J, Hashimshony T, Yanai I, Colaiácovo MP. Spatiotemporal Gene Expression Analysis of the Caenorhabditis elegans Germline Uncovers a Syncytial Expression Switch. Genetics. 2018;210:587-605.

van Nocker S, Sadis S, Rubin DM, Glickman M, $\mathrm{Fu} \mathrm{H}$, Coux O, et al. The multiubiquitinchain-binding protein Mcb1 is a component of the $26 \mathrm{~S}$ proteasome in Saccharomyces cerevisiae and plays a nonessential, substrate-specific role in protein turnover. Mol Cell Biol. 1996;16:6020-8.
Voronina E. The diverse functions of germline Pgranules in Caenorhabditis elegans. Mol Reprod Dev. 2013;80:624-31.

Wang L, Eckmann CR, Kadyk LC, Wickens M, Kimble J. A regulatory cytoplasmic poly(A) polymerase in Caenorhabditis elegans. Nature. 2002;419:312-6.

Wang S, Kimble J. The TRA-1 transcription factor binds TRA-2 to regulate sexual fates in Caenorhabditis elegans. EMBO J. 2001;20: 1363-72.

Wang X, Voronina E. Diverse Roles of PUF Proteins in Germline Stem and Progenitor Cell Development in C. elegans. Front Cell Dev Biol. 2020;8:29.

White J. Of worms and men. J Neurogenet. 2020; 34(3-4):255-8.

White-Grindley E, Li L, Mohammad Khan R, Ren F, Saraf A, Florens L, et al. Contribution of Orb2A stability in regulated amyloid-like oligomerization of Drosophila Orb2. PLoS Biol. 2014;12:e1001786.

Wu J, Campbell ZT, Menichelli E, Wickens M, Williamson JR. A protein.protein interaction platform involved in recruitment of GLD-3 to the FBF.fem-3 mRNA complex. J Mol Biol. 2013;425:738-54
Xu W, Long L, Zhao Y, Stevens L, Felipe I, Munoz $\mathrm{J}$, et al. Evolution of Yin and Yang isoforms of a chromatin remodeling subunit precedes the creation of two genes. Elife. 2019;8.

Zanetti S, Meola M, Bochud A, Puoti A. Role of the $C$. elegans U2 snRNP protein MOG-2 in sex determination, meiosis, and splice site selection. Dev Biol. 2011;354:232-41.

Zanetti S, Grinschgl S, Meola M, Belfiore M, Rey $\mathrm{S}$, Bianchi P, et al. The sperm-oocyte switch in the C. elegans hermaphrodite is controlled through steady-state levels of the fem-3 mRNA. RNA. 2012;18:1385-94.

Zanin E, Pacquelet A, Scheckel C, Ciosk R, Gotta M. LARP-1 promotes oogenesis by repressing fem-3 in the C. elegans germline. J Cell Sci. 2010;123:2717-24.

Zarkower D. Hodgkin J: Molecular analysis of the C. elegans sex-determining gene tra-1: a gene encoding two zinc finger proteins. Cell. 1992; 70:237-49.

Zarkower D. Somatic sex determination. WormBook. 2006;1-12.

Zhang B, Gallegos M, Puoti A, Durkin E, Fields S, Kimble J, et al. A conserved RNA-binding protein that regulates sexual fates in the C. elegans hermaphrodite germ line. Nature. 1997; 390:477-84. 